\title{
PERILAKU PRONOMINA PERSONA /ITE/ UNTUK MENYATAKAN ASPEK DAN KEPEMILIKAN DALAM STRUKTUR KALIMAT BAHASA SASAK MASBAGIK
}

\author{
Hani Agustina \\ Magister Pendidikan Bahasa Indonesia \\ Universitas Mataram \\ Jl. Pemuda No. 35 Mataram 83125, Nusa Tenggara Barat \\ Email: hani.agustina13@gmail.com
}

\begin{abstract}
This study focuses on the behavior of pronouns persona /te/ to express aspects and possessions in the structure of the Masbagic sasak language sentence. This research is descriptive conducted solely based on the facts that exist or the phenomenon that empirically live on the speakers. Researchers describe the data contained in the systematic data related to the problems studied. Data collection referred to the technique of lively cognate and recording techniques. Data were analyzed using intralingual pad method, presenting the result on informal method. The results are pronomina persone has a clitic form of proclitik te- and enclitik -te. When the pronominal persona of the proclical form meets with the verb it will express an aspect and there will be phoneme changes in the verb. When the pronouns persona of the enclosed form meets the nouns it will declare an ownership that there will be an addition of phoneme $/ \mathrm{n} /$ if the word attached ends in the vowel and there is no phoneme change in the noun attached if the consonant ends.
\end{abstract}

Keywords: behavior pronomina persona, aspect, ownership

DOI: 10.30957/lingua.v15i1.427.

\section{PENDAHULUAN}

Bahasa Sasak Masbagik memiliki beberapa keunikan yang tidak dimiliki oleh bahasa lain. Keunikan tersebut seperti; sistem ujaran lambang fonologi yang cukup sulit ditiru oleh masyarakat yang bukan penututr asli; bentuk pronomina persona pertama tunggal tiang untuk bahasa halus tidak dimiliki; perbedaan penggunan bentuk dan letak pronomina persona.

Bahasa Sasak Masbagik memiliki bentuk dan struktur yang berbeda dengan bahasa Indonesia. Bentuk yang berbeda ini membuat bahasa Sasak memiliki bentuk pronomina persona yang sangat kontras dengan bahasa Indonesia. Menurut Chaer (2008:87) pronomina persona lazim disebut kata ganti karena tugasnya memang menggantikan nomina yang ada. Sejalan dengan ini Alwi (2003:249) mengatakan bahwa pronomina persona adalah pronomina yang dipakai untuk mengacu pada orang. 
Bentuk pronomina persona dalam bahasa Sasak khususnya bahasa Sasak di Kecamatan Masbagik memiliki bentuk yang berbeda dengan bentuk pronomina persona bahasa Indonesia. Menurut Alwi (2003:249) pronomina persona dapat mengacu pada diri sendiri (pronomina persona pertama), mengacu pada orang yang diajak bicara (pronomina persona kedua), atau mengacu pada orang yang dibicarakan (pronomina persona ketiga). Kata ganti diri dalam bahasa Sasak masbagik tersebut antara lain; kata ganti diri orang pertama tunggal yaitu $e k u$ [Eku] yang berarti aku atau saya; orang pertama jamak yaitu ite [itE] yang berarti kami atau kita. Kata ganti orang kedua tunggal yaitu kemu [kEmu], ente [EntE] dan ide [idE] yang berarti kamu; orang kedua jamak, yaitu ide pede [idE pEdE] berarti kamu sekalian. Sedangkan kata ganti diri orang ketiga tunggal yaitu iye [iyE] yang berarti dia; orang ketiga jamak, yaitu ye pede [yE pEdE] berarti mereka.

Kata ganti orang pertama jamak yaitu ite [itE] Pronomina persona /ite/ memilki variasi bentuk, yaitu te- dan -te. Bentuk klitika te- dan -te ini memiliki fungsi masingmasing. Adapun fungsinya; penanda lingual /te/ sebagai klitika atau prefiks memilki perilaku yang berbeda jika melekat pada kata. Pertama, ketika ia sebagai awalan (prefiks) jika melekat pada verba maka verba yang dilekati tidak akan mengalami perubahan (penambahan atau peluluhan) fonem. Kedua, ia merupakan bentuk pronomina persona yang menyatakan aspek (penanda waktu) saat melekat pada verba yang ada di belakangnya ia akan membuat verba yang dilekatinya mengalami perubahan fonem jika verba tersebut berupa verba transitirf sedangkan jika verba tersebut berupa verba intransitif maka tidak terjadi perubahan fonem. Ketiga, bentuk klitika dalam konstruksi kepemilikan jika melekat pada kata benda (nomina) dan akan mengalami perubahan fonem pada nomina yang berakhiran vokal dan tidak mengalami perubahan fonem pada nomina yang berakhiran konsonan. Keempat, Sebagai bentuk pronomina persona yang menyatakan penanda waktu dan membuat verba yang melekat di depannya tidak mengalami perubahan fonem.

Penelitian yang mengkaji tentang distribusi pronomina dalam menyatakan aspek di dalam sebuah kalimat dalam bahasa Sasak Masbagik pernah dilakukan sebelumnya oleh peneliti sendiri pada semua bentuk pronomina personanya. Aspek menyangkut salah satu segi dari apa yang diartikan oleh verba, yaitu: adanya (kegiatan atau kejadian), mulainya, terjadinya (atau dilaksanakannya), berlangsungnya, selesai tidaknya, adanya hasil atau tidak, dan adanya kebiasaan (Verhaar, 2001:127). Menurut Tadjuddin (2005:8) dan Sumarlam (2004:28) aspektualitas menggambarkan dua gejala luar bahasa yang berupa unsur waktu (time, temporal, moments) dan situasi (event, action, process, sctivity). Adapun unsur waktu, seperti yang tampak pada definisi Comrie (dalam Tadjuddin, 2005:9) adalah waktu internal, yang sifatnya, sesuai dengan keragaman sifat situasi, yakni gejala luar bahasa, yang dalam bentuk bahasa diungkapkan melalui berbagai bentuk verba dalam kalimat.

Setelah melakukan kajian lebih mendalam, peneliti menemukan kekurangan khususnya pada pronomina persona /ite/ terkait pada proses morfofonemis yang tidak ditemukan dan pada bentuk te- yang menyatakan aspek kepemilikan. Oleh karena itu 
untuk mengembangkan penelitian sebelumnya peneliti berfokus pada pronomia persona /ite/ dengan variasi bentuknya yang memiliki fungsi masing-masing pada perilaku yang ditunjukkan dan posisi pronomina dan penentuan aspek tidak terlepas dari konteks komunikasi penutur. Selain itu alasan utama peneliti mengangkat permasalahan ini karena peneliti adalah penutur asli bahasa Sasak masbagik. Alasan utama peneliti mengankat permasalahan ini karena peneliti adalah penutur asli bahasa Sasak masbagik. Hal ini akan mendukung keabsahan data yang akan memperkuat kajian penelitian dan kedalaman analisis yang akan dilakukan.

Dalam penelitian ini peneliti akan melakukan pemilihan dan pengolahan data yang sudah ada pada penelitian sebelumnya serta melakukan obeservasi kepada informan yang merupakan penutur asli bahasa Sasak Masbagik untuk kelengkapan data.

Berdasarkan pemaparan di atas, tujuan penelitian ini, yaitu untuk mengetahui bagaimanakah perilaku pronomina persona /te/ untuk menyatakan aspek dan kepemilikan dalam struktur kalimat bahasa sasak Masbagik.

\section{METODE}

Jenis penelitian yang dilakukan dalam penelitian ini adalah penelitian deskriptif. Penelitian ini akan mendeskripsikan distribusi pronomina persona untuk menyatakan aspek di dalam struktur kalimat bahasa Sasak. Sumber data dalam penelitian ini adalah penutur asli bahasa Sasak Masbagik. Informan yang digunakan adalah penutur asli.

Dalam penelitian ini metode pengumpulan data yang digunakan adalah metode simak. Peneliti akan menyimak penggunaan bahasa. Beberapa teknik yang akan dilakukan dalam penggunaan metode ini, yaitu:

a. Teknik Simak Libat Cakap

Peneliti akan secara langsung terlibat dalam komunikasi yang berlangsung dalam pengempulan data yang dilakukan. Hal ini dimaksudkan untuk mempermudah peneliti selama pengumpulan data. Teknik ini dipadukan dengan teknik pancing. Teknik pancing yaitu suatu teknik yang menggunakan strategi pemberian stimulan kepada informan untuk mendapatkan data yang dimaksudkan.

b. Teknik Catat

Teknik catat ini digunakan agar data yang telah didapatkan dapat disimpan dengan rapi dan memudahkan pengklasifikasian data. Media yang digunakan dalam teknik catat ini adalah telepon genggam dan alat tulis.

Metode analisis data yang digunakan adalah metode padan intralingual. Metode ini digunakan dengan cara membandingkan unsur-unsur yang bersifat lingual. Dalam hal ini data-data yang diperoleh, peneliti akan membandingkan letak satuan lingual khususnya pronomina persona di dalam beberapa unsur-unsur bahasa yang berbeda. Metode penyajian hasil analisis data menggunakan metode informal. Metode informal yaitu penyajian hasil analisis dengan menggunakan kata-kata berbentuk penjabaran analisis. 
Http://lingua.pusatbahasa.or.id; Email:presslingua@gmail.com Center of Language and Culture Studies, Surakarta, Indonesia

Agustina, Hani. 2018. Perilaku Pronomina Persona /ITE/ untuk Menyatakan Aspek dan Kepemilikan dalam Struktur Kalimat Bahasa Sasak Masbagik. Lingua (2018), 15(1): 19 28. DOI: 10.30957/lingua.v15i.427.

\section{HASIL DAN BAHASAN}

Wujud data berdasarkan permasalahan pada penelitian ini akan dijabarkan pada tabel 1 di bawah ini.

Tabel 1. Perilaku Pronomina ITE Kalimat Bahasa Sasak Masbagik

\begin{tabular}{|c|c|c|c|c|c|}
\hline \multirow{3}{*}{ Kata } & \multirow{3}{*}{ Glos } & \multicolumn{3}{|c|}{ Klitika } & \multirow{3}{*}{$\begin{array}{c}\text { awalan } \\
/ \text { te/ }\end{array}$} \\
\hline & & \multicolumn{2}{|c|}{$\begin{array}{l}\text { Proklitik } \\
/ \text { te/ }+ \text { V/N }\end{array}$} & \multirow[t]{2}{*}{ Enklitik } & \\
\hline & & $\begin{array}{c}\text { Verba } \\
\text { transitif }\end{array}$ & $\begin{array}{c}\text { Verba } \\
\text { intransitif }\end{array}$ & & \\
\hline Bait & Ambil & te mbait & & & tebeit \\
\hline Bayar & Bayar & te mbayar & & & tebayar \\
\hline Bece & Baca & te mbece & & & tebeli \\
\hline Inem & Minum & te nginem & & & Teinem \\
\hline Idap & Rasa & te ngidap & & & Teidap \\
\hline Irup & hirup/cicip & te ngirup & & & Teirup \\
\hline Kaken & Makan & te ngaken & & & tekaken \\
\hline Kelaq & Rebus & te ngelaq & & & tekelaq \\
\hline Kelek & Panggil & te ngelek & & & tekelek \\
\hline Saur & Bayar & te nyaur & & & Tesaur \\
\hline Saut & Lempar & te neteh & & & Teteteh \\
\hline Serok & & te nyerok & & & teserok \\
\hline Turun & Turun & te nurunang & te turun & & \\
\hline Taek & Naik & te naikang & te taek & & \\
\hline Teteh & Buang & te neteh & & & Teteteh \\
\hline Tokol & Duduk & te nokolang & te tokol & & \\
\hline Tindok & Tidur & te nindoang & te tindoq & & \\
\hline Buku & Buku & & & Bukunte & \\
\hline Sepede & Sepeda & & & Sepedente & \\
\hline Apel & & & & Apelte & \\
\hline
\end{tabular}

Berikut akan dijabarkan perilaku pronomina persona /ite/ untuk menyatakan aspek dan kepemilikan dalam struktur kalimat bahasa Sasak Masbagik. 


\section{Perilaku Pronomina Persona /ite/ untuk Menyatakan Aspek}

Ketika pronomina persona bentuk proklitik bertemu dengan verba maka akan menyatakan sebuah aspek (tanpa penanda lingual aspek seperti; gen (akan), jengke (sedang), wah(sudah)) dan akan terjadi perubahan fonem pada verbanya.

\section{a. Analisis perilaku pronomina persona te- untuk menyatakan aspek}

\section{Data 1}

(1) tembait almamater.

(2) Tembayar gule

Dilihat dari teks di atas proklitik te-ketika bertemu dengan verba bait. Dalam struktur kalimat ini penggunaan proklitik te- sebelum verba (V) menyatakan sebuah aspek akan melakukan suatu kegiatan.

a) te-

(kita)

te-

(kita)

$$
+
$$

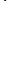

$\stackrel{+}{t}$

(Akan) bait

(ambil)

mbait

(mengambil)

bayar

(bayar)

mbayar

(membayar)

(kita)

$\begin{array}{ll}\text { te- } & + \\ \text { (kita) } & \\ \text { te- } & + \\ \text { (kita) } & +\end{array}$

\section{Data 2}

(3) tenginem

(4) Tengidap

(5) tengirup

Dilihat dari teks di atas proklitik te- ketika bertemu dengan verba inem, idap, irup, penggunaan proklitik te- sebelum verba (V) menyatakan sebuah aspek akan melakukan suatu kegiatan.

c) te(kita) te-

d) te-

(kita)

te-

(kita) inem

(minum)

nginem

(meminum)

idap

(rasa)

ngidap

(merasakan) 


\section{Data 3}

\section{(Akan)}

(6) tengaken

(7) Tengelaq

(8) Tengelek

Dilihat dari teks di atas proklitik te- ketika bertemu dengan verba kaken, kelaq, kelek, penggunaan proklitik te- sebelum verba (V) menyatakan sebuah aspek akan melakukan suatu kegiatan.

e) te-

\begin{tabular}{|c|c|c|}
\hline $\begin{array}{l}\text { te- } \\
\text { (kita) }\end{array}$ & + & $\begin{array}{l}\text { kaken } \\
\text { (makan) }\end{array}$ \\
\hline $\begin{array}{l}\text { te- } \\
\text { (kita) }\end{array}$ & + & $\begin{array}{l}\text { ngaken } \\
\text { (memakan) }\end{array}$ \\
\hline
\end{tabular}

f) te-

(kita)

kelaq

(rebus)

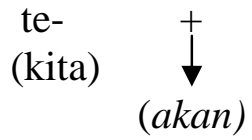

ngelaq

g) te-

$+$

(merebus)

(kita)

kelek

te-
(kita)

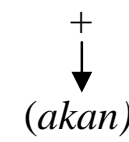

(panggil)

kelek

(memanggil)

\section{Data 4}
(9) tenyaur
(10) Tenyaut
(11) Tenyir

Dilihat dari teks di atas proklitik te- ketika bertemu dengan verba saur, saut, siram, penggunaan proklitik te- sebelum verba (V) menyatakan sebuah aspek akan melakukan suatu kegiatan.

h) te$+$

saur

(kita)

(bayar)

te-

(kita)

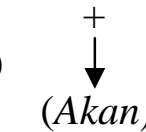

nyaur

(membayar)

i) te-

saut

(kita)

(lempar) 
Http://lingua.pusatbahasa.or.id; Email: presslingua@gmail.com

$\begin{array}{lc}\text { te- } & + \\ \text { (kita) } & \stackrel{+}{+} \\ & \text { Akan })\end{array}$

j) te-

(kita)

$+$

te-

(kita) nyaut

(melempar)

siram

(siram)

nyiram

(menyiram)

Data 5

(12) teneteh

(13) Tenokolang

(14) Tenindo'ang

Dilihat dari teks di atas proklitik te- ketika bertemu dengan verba teteh, tokol, tindok, penggunaan proklitik te- sebelum verba $(\mathrm{V})$ menyatakan sebuah aspek akan melakukan suatu kegiatan.

k) te

(kita)

te-

(kita)

a)

(Akan)

1) te-

(kita)<smiles>[13CH3]</smiles>

te-

(kita)<smiles>[14CH3]</smiles>

te-
(kita)

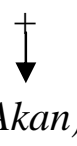

m) te-

(kita)

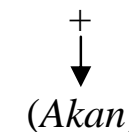

te-

(kita) teteh

(buang)

neteh

(membuang)

tokol

(duduk)

nokol

(duduk)

nokolang

(mendudukkan)

tindok

(tidur)

nindo'ang

(menidurkan) 


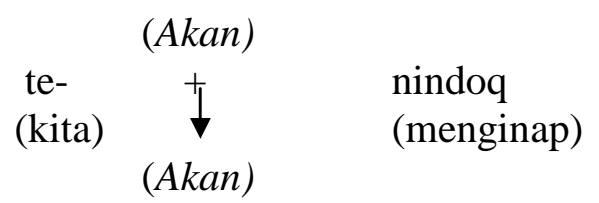

Khusus contoh data pada kata tindoq dalam menyatakan aspek akan berlangsung perubahan untuk kata tersebut menjadi nindoq akan berarti akan menginap, karena di dalam bahasa Indonesia tidak ada kata *menidur melainkan ada kata menidurkan atau meniduri yang jika dipadankan dalam bahasa Sasak masbagik menjadi nindo'ang atau nindo'in.

\section{b. Analisis bentuk verba}

Proklitik te- bertemu dengan verba yang huruf awalnya /b/ yaitu bait dan bayar mengalami penambahan fonem $/ \mathrm{m} /$
(1) tembait almamater
$:$ te + bait $\rightarrow$ tembait
(2) tembayar gule
$:$ te + bayar $\rightarrow$ tembayar

$>$ Proklitik te- bertemu dengan verba yang huruf awalnya /i/ yaitu idap dan inem mengalami perubahan fonem /ng/
(3) tengidap
$:$ te + idap $\rightarrow$ tengidap
(4) tenginem
$:$ te + inem $\rightarrow$ tenginem

$>$ Proklitik te- bertemu dengan verba yang huruf awalnya /k/ yaitu kaken dan kelaq mengalami perubahan fonem /ng/

(5) tengaken : te + kaken $\rightarrow$ tengaken

(6) tengelaq : te + kelaq $\rightarrow$ tengelaq

$>$ Proklitik te- bertemu dengan verba yang huruf awalnya /s/ yaitu saur dan siram mengalami perubahan fonem /ny/

(7) tenyaur : te + saur $\rightarrow$ tenyaur

(8) tenyiram : te + siram $\rightarrow$ tenyiram

$>$ Proklitik te- bertemu dengan verba yang huruf awalnya /t/ yaitu teteh, tokol, dan tindoq mengalami perubahan fonem $/ \mathrm{n} /$
(9) teneteh
$:$ te + teteh $\rightarrow$ teneteh
(10) tenokol
$:$ te + tokol $\rightarrow$ tenokol
(11) tenindoq
$:$ te + tindoq $\rightarrow$ tenindoq

\section{Perilaku Pronomina Persona /ite/ untuk Menyatakan Kepemilikan}

Ketika pronomina persona bentuk enklitik bertemu dengan nomina maka akan menyatakan sebuah kepemilikan akan terjadi penambahan fonem /n/ jika kata yang dilekatinya berakhiran vokal dan tidak terjadi perubahan fonem pada nomina yang dilekatinya jika berakhiran konsonan.
$>$ Buku + te $\rightarrow$ bukunte
$\rightarrow$ Sepede + te $\rightarrow$ sepedente
$>$ Bale + te $\rightarrow$ balente
Soto + te $\rightarrow$ sotonte 
$\rightarrow$ Apel + te $\rightarrow$ apelte

Kompor + te $\rightarrow$ komporte

\section{Perilaku bentuk te- sebagai awalan}

Bentuk te- yang berfungsi sebagai awalan jika dipadankan dengan bahasa Indonesia sama dengan di-. Awalan te- yang terletak di depan verba tidak akan mengalami perubahan fonem beda halnya dengan verba yang mengalami perubahan fonem akan menyatakan sebuah aspek waktu. Berikut beberapa data yang ditemukan.

$\begin{array}{lll}>\mathrm{Te}+\mathrm{inem} & \rightarrow \text { teinem } & \text { 'diminum' } \\ >\mathrm{Te}+\mathrm{idap} & \rightarrow \text { teidap } & \text { 'dirasa' } \\ >\mathrm{Te}+\mathrm{irup} & \rightarrow \text { teirup } & \text { 'dihirup' } \\ >\mathrm{Te}+\mathrm{kaken} & \rightarrow \text { tekaken } & \text { 'dimakan' } \\ >\mathrm{Te}+\mathrm{kelaq} & \rightarrow \text { tekelaq } & \text { 'direbus' } \\ >\mathrm{Te}+\mathrm{kelek} & \rightarrow \text { tekeleq } & \text { 'dipanggil' } \\ >\mathrm{Te}+\mathrm{saur} & \rightarrow \text { tesaur } & \text { 'dibayar' } \\ >\mathrm{Te}+\text { teteh } & \rightarrow \text { teteteh } & \text { 'dibuang' }\end{array}$

\section{SIMPULAN}

Berdasarkan hasil analisis yang telah dilakukan, maka dapat disimpulkan bahwa pronomina persona ite memilki bentuk klitika yaitu proklitik te- dan enklitik -te. Ketika pronomina persona bentuk proklitik bertemu dengan verba maka akan menyatakan sebuah aspek (tanpa penanda lingual aspek seperti; gen (akan), jengke (sedang), wah(sudah)) dan akan terjadi perubahan fonem pada verbanya. Ketika pronomina persona bentuk enklitik bertemu dengan nomina maka akan menyatakan sebuah kepemilikan akan terjadi penambahan fonem /n/ jika kata yang dilekatinya berakhiran vokal dan tidak terjadi perubahan fonem pada nomina yang dilekatinya jika berakhiran konsonan

\section{DAFTAR PUSTAKA}

Alwi, Hasan dkk. 2003. Tata Bahasa Baku Bahasa Indonesia Edisi Ketiga. Jakarta: Pusat Bahasa dan Balai Pustaka.

Chaer, Abdul. 2008. Morfologi Bahasa Indonesia. Jakarta: PT. Rineka Cipta.

Idris, Nuny Sulistiany. 2009. Ihwal Aspektualitas, Temporalitas, Dan Modalitas dalam

Bahasa Indonesia. Bandung: Universitas Padjadjaran Bandung. Makalah

Tadjuddin, Moh. 2005. Aspektualitas dalam Kajian Linguistik. Bandung: PT. Alumni.

Sumarlam, M.S. 2004. Aspektualitas Bahasa Jawa Kajian Morfologis dan Sintaksis.

Surakarta: Pustaka Cakra Surakarta.

Verhaar, J. W. M. 2001. Asas-Asas Linguistik Umum. Gadjah Mada University Press. Mada University Press. 
LINGUA, Vol. 15, No. 1, Maret 2018

p ISSN: 1979 9411; e ISSN: 2442 238X

Http://lingua.pusatbahasa.or.id; Email:presslingua@gmail.com Center of Language and Culture Studies, Surakarta, Indonesia

Agustina, Hani. 2018. Perilaku Pronomina Persona /ITE/ untuk Menyatakan Aspek dan Kepemilikan dalam Struktur Kalimat Bahasa Sasak Masbagik. Lingua (2018), 15(1): 19 28. DOI: 10.30957/lingua.v15i.427. 